\title{
Serum PON-1 Activity but not Q192R Polymorphism is Related to the Extent of Atherosclerosis
}

\author{
Ahmet Bayrak¹, Tülin Bayrak¹, S Lale Tokgözoğlu², Bilge Volkan-Salancı ${ }^{3}$, Ali Deniz², Bünyamin Yavuz², \\ Mehmet Alikaşifoğlu ${ }^{3}$ and Ediz Demirpençe ${ }^{1}$
}

\author{
${ }^{1}$ Department of Biochemistry, Faculty of Medicine, Hacettepe University, Ankara, Turkey \\ ${ }^{2}$ Department of Cardiology, Faculty of Medicine, Hacettepe University, Ankara, Turkey \\ ${ }^{3}$ Department of Medical Genetics, Faculty of Medicine, Hacettepe University, Ankara, Turkey
}

\begin{abstract}
Aim: Paraoxonase-1 (PON1) is an antioxidant enzyme located in high density lipoprotein (HDL). PON1 was defined as a protective factor against atherosclerosis. The aim of this study was to investigate the possible relationship between serum paraoxonase (PONase), homocysteine thiolactonase (HTase) activities and PON1 Q192R polymorphism, and the extent and severity of atherosclerosis. Methods: Blood specimens were collected from 142 individuals who had no coronary artery lesions angiographically (control group) and 128 individuals who had angiographically documented coronary artery disease of several degrees (patient group). The extent and severity of arterial lesions were evaluated by the Gensini scoring system. PONase and HTase activities were measured in serum using a spectrophotometric method. PON1 Q192R polymorphism was evaluated using PCR-RFLP after DNA isolation from blood.

Results: Serum PONase and HTase activities were significantly lower in the patient group than in healthy controls $(135.7 \pm 56.0 \mathrm{U} / \mathrm{mL}$ vs $153.8 \pm 62.0 \mathrm{U} / \mathrm{mL}, p<0.05 ; 36.0 \pm 6.1 \mathrm{U} / \mathrm{mL}$ vs $43.0 \pm 4.04$ $\mathrm{U} / \mathrm{mL}, p<0.01$; respectively). In the patient group, there was a negative correlation between PONase, HTase activities and the Gensini score $(r=-0.168, p=0.039 ; r=-0.164, p=0.006$, respectively). In both groups, there was no significant difference in the distribution of PON1 Q192R polymorphism. In the patient group, the distribution of Gensini scores according to genotypes was not significant.
\end{abstract}

Conclusion: It has been concluded that serum PONase and HTase activities might be a more relevant marker than PON1 genotype in evaluating the extent and severity of atherosclerosis.

J Atheroscler Thromb, 2012; 19:376-384.

Key words; Paraoxonase, Homocysteine thiolactonase, Atherosclerosis, Polymorphism

\section{Introduction}

Paraoxonase 1 (PON1) is a $\mathrm{Ca}^{2+}$-dependent serum esterase that is tightly associated with high density lipoprotein $(\mathrm{HDL})^{1,2)}$. PON1 hydrolyzes a broad range of substrates such as aryl esters (including phenyl acetate), nerve agents, lactones, and organophosphate oxons (e.g., chlorpyrifos oxon, diazoxon and

Address for correspondence: Ahmet Bayrak, PhD, Department of Biochemistry, Faculty of Medicine, Hacettepe University, Ankara, 06100 Turkey

E-mail: ahmetb@hacettepe.edu.tr

Received: August 9, 2011

Accepted for publication: October 25, 2011 paraoxon); however, its physiological substrates have not yet been fully identified ${ }^{1,3)}$.

HDL-bound PON1 inhibits low density lipoprotein (LDL) oxidation ${ }^{4-6)}$ and stimulates cholesterol efflux from macrophages ${ }^{7}$. PON1 knockout mice are highly susceptible to atherosclerosis ${ }^{8,9)}$. Jakubowski ${ }^{10)}$ suggested that PON1 possesses thiolactonase activity, hydrolyzing homocysteine thiolactone (HTL) to homocysteine (Hcy). Excess Hcy generates HTL, a chemically reactive metabolite that acylates free amino groups of lysine residues, causing protein alterations and cellular damage. It has been shown that HTL can homocysteinylate LDL, leading to its aggregation and enhanced uptake by endothelial cells in vitro ${ }^{10)}$. Thus, 
hydrolyzing homocysteine thiolactone may be an important, if not the principal mechanism of the protective activity of PON1 against atherosclerosis ${ }^{11,12}$.

Human PON1 has several genetic polymorphisms, two of which result in amino acid substitutions at positions 55 and 192 in PON1 proteins ${ }^{13,14)}$. Some substrates, such as paraoxon and fenitroxon, are hydrolyzed faster by the PON1 192R allozyme, whereas other substrates such as phenyl acetate are hydrolyzed at the same rate by both allozymes, and yet others, such as soman and sarin, are hydrolyzed more rapidly by the PON1 192Q allozyme ${ }^{13,14)}$. R allozyme is less efficient at preventing the oxidation of $\mathrm{LDL}$ than the Q allozyme because of the decreased hydrolysis of lipid peroxides $\left.{ }^{13}, 14\right)$.

Hypothesized differences in the ability of the polymorphic forms to protect the oxidation of $\mathrm{LDL}$ have led to numerous studies attempting to determine the relationship between PON1 polymorphism and cardiovascular disease ${ }^{4,13,15-26)}$. These studies have yielded apparently conflicting results. Unfortunately, the majority of these studies were exclusively genetic, with no evaluation of enzyme activity. Investigating only the association between PON1 polymorphism and vascular disease may not adequately assess the protective effect of the enzyme, which has led to the proposal that the PON1 status (reflecting activity and genotype) rather than genotype alone may be more important in determining atherosclerosis risk.

Previously, a limited number of studies dealt with both the activity and polymorphism of PON $\left.1{ }^{13}, 17,19,20,23-25\right)$ and in all these studies paraoxonase activity (PONase) was measured using paraoxon. We considered that using HTL, an endogenous substrate, would be more appropriate to evaluate the protective role of PON1 against atherosclerosis than the assay that uses paraoxon, an exogenous substrate.

\section{Aim}

Thus, the aim of this study was to investigate the relationship between the PON1 status (serum PON1ase, HTase activities and PON1 Q192R polymorphism) and the extent and severity of atherosclerosis.

\section{Methods}

\section{Subjects and the Evaluation of Coronary Arteries}

Two hundred seventy subjects, who underwent diagnostic coronary angiography at the Department of Cardiology with the aim of finding the etiology of chest pain were included in the study. All subjects were in a stable condition and non-smokers. None of the subjects had sustained myocardial infarction within 6 months before taking part in the study. Patients with acute coronary syndromes, hepatic disorders, endocrinological or renal disorders, diabetes mellitus or impaired glucose tolerance, inflammatory or malignant diseases were excluded. The study was approved by the Hacettepe University Faculty of Medicine Ethics Committee (04.11.2004, FON 04/26-14) and all subjects gave informed consent. In the patient group with coronary artery disease (CAD), 73 were receiving a $\beta$-adrenoceptor-blocking drug, 32 were taking a calcium channel blocker, and 74 were on lipid-lowering therapy (statins but no fibrates). In the control group, 25 were receiving a $\beta$-adrenoceptor-blocking drug, 22 were taking a calcium channel blocker, and 25 were on lipid-lowering therapy (statins but no fibrates). Clinical and demographic features of the subjects were enrolled. Coronary angiography was performed using the Judkins method. The extent and severity of arterial lesions were evaluated by the Gensini scoring sys$t^{27)}$, which is widely used for this purpose ${ }^{28)}$. Briefly, according to this scoring system, the coronary arterial tree was divided into segments. The functional importance and luminal narrowing percentage of arteries in given segments were evaluated and scores were calculated. Higher Gensini scores represented more severe disease. One hundred forty-two of the subjects had no evidence of coronary arterial lesions (Gensini score $=0$, control group), while 128 had lesions of different degrees of severity (coronary artery disease group). Lipid profile was evaluated by the Laboratory of Clinical Pathology in Hacettepe University Hospital. Cholesterol and HDL-cholesterol (HDL) levels were measured spectrophotometrically by Roche Modular Systems. Cholesterol levels were determined by an enzymatic method using cholesterol esterase and cholesterol oxidase. HDL was also determined by an enzymatic method using cholesterol esterase and cholesterol oxidase coupled with PEG to the amino groups.

\section{Sample Preparation}

Blood samples were obtained during coronary angiography and collected either without any additives or into EDTA-containing tubes. Samples for activity assay were centrifuged at $3500 \mathrm{xg}$ for $10 \mathrm{~min}$ utes. The serum was removed and stored at $-20^{\circ} \mathrm{C}$. Blood for DNA isolation was collected into EDTAcontaining tubes and DNA was extracted from peripheral blood leukocytes using a commercial kit (Promega, ABD). Isolated DNA samples were stored frozen at $-80^{\circ} \mathrm{C}$. 


\section{PONase Activity}

PONase activity was measured according to Gan et al. $^{29)}$ using paraoxon $(O, O$-diethyl- $O-p$-nitrophenylphosphate; Sigma) as a substrate at a final concentration of $1 \mathrm{mM}$. Formation of $p$-nitrophenol at $37^{\circ} \mathrm{C}$ was monitored at $412 \mathrm{~nm}$ in the presence of $100 \mathrm{mM}$ Tris- $\mathrm{HCl}$ ( $\mathrm{pH} 8.0$ ) containing $1 \mathrm{mM} \mathrm{CaCl} 2$ and $1 \mathrm{mM} \mathrm{NaCl}$. Enzymatic activity was calculated from the molar extinction coefficient of $p$-nitrophenol $\left(\epsilon_{412}=18290 \mathrm{M}^{-1}\right.$ $\mathrm{cm}^{-1}$ ) and corrected for non-enzymatic hydrolysis. One unit of paraoxonase activity is defined as $1 \mathrm{nmol}$ of substrate hydrolyzed per min, under the defined assay conditions.

\section{HTase Activity}

HTase activity was measured spectrophotometrically using a modification of the method described by Billecke ${ }^{30}$. HTL (Sigma) was used as a substrate at a final concentration of $2 \mathrm{mM}$ in $50 \mathrm{mM}$ Hepes buffer ( $\mathrm{pH}$ 7.4). Thiolactone hydrolysis was measured at $37^{\circ} \mathrm{C}$ using Ellman's procedure ${ }^{31)}$ to monitor the accumulation of free sulfhydryl groups reacting with DTNB at $412 \mathrm{~nm}$. Enzymatic activity was calculated from the molar extinction coefficient of DTNB $\left(\epsilon_{412}\right.$ $=13600 \mathrm{M}^{-1} \mathrm{~cm}^{-1}$ ) and corrected for non-enzymatic hydrolysis. One unit of HTase activity is defined as 1 $\mu \mathrm{mol}$ of substrate hydrolyzed per min under the defined assay conditions.

\section{Determination of PON1 Genotypes}

Standard PCR protocols, followed by restriction enzyme digestion, were used to genotype the Q192R PON1 polymorphism, as previously described ${ }^{32)}$. Briefly, the primer pairs used for Q192R were F 5' TAT TGT TGC TGT GGG ACC TAG-3' and R 5' Bt- CAC GCT AAA CCC AAA TAC. Each PCR reaction contained $200 \mu \mathrm{M}$ dNTP, $0.2 \mu \mathrm{M}$ primer, 10 $\mathrm{mM}$ Tris- $\mathrm{HCl}, 500 \mathrm{mM} \mathrm{KCl,} \mathrm{\% 5} \mathrm{dimethyl} \mathrm{sulfoxide,}$ $1.5 \mathrm{mM} \mathrm{MgCl}_{2}$, and $1.25 \mathrm{U}$ Taq polymerase (Promega). The PCR conditions were $94^{\circ} \mathrm{C}$ for $4 \mathrm{~min}, 30$ cycles of $94^{\circ} \mathrm{C}$ for $60 \mathrm{~min}, 50^{\circ} \mathrm{C}$ for $90 \mathrm{~min}, 72^{\circ} \mathrm{C}$ for $2 \mathrm{~min}$, followed by $72^{\circ} \mathrm{C}$ extension for $7 \mathrm{~min}$. PCR products were digested with Alw1 and digested products were resolved by gel electrophoresis.

\section{Statistics}

All analyses were performed using SPSS software, version 11.0. $P$ values less than 0.05 were judged as significant. Continous variables with normal distribution are expressed as the mean $\pm S D$, variables with skew distribution are expressed as the median (minimum-maximum), and categorical variables are expressed as a percentage. The Mann Whitney $U$ test and independent samples $t$ test were applied for comparisons between study groups. The correlation between two numeric variables was calculated by either Pearson's correlation coefficient test or Spearman's rho correlation. The Hardy-Weinberg equilibrium, allele frequency and genotype distributions were tested by the chi-square test. The relationship between the PON1 genotype and the Gensini score was evaluated using Kruskal-Wallis analysis. The associations between genotypes and PONase/HTase activities were tested using the Jonckheere-Terpstra trend test.

\section{Results}

Different degrees of coronary artery lesions were established angiographically in 128 out of 270 participants. The severity and extent of coronary artery disease in these 128 patients were evaluated according to the Gensini scoring system while 142 participants with normal coronary arteries had score 0 and were defined as the control group. The biochemical and demographic features of the subjects are shown in Table 1. Plasma levels of HDL, the protective lipoprotein against cardiovascular disease, were significantly higher in the control group than in patients who had CAD $(p<0.05)$; however, no significant correlation was determined between HDL levels and Gensini scores (Table 2). The ratio of total cholesterol to HDL is considered to be a better marker than HDL alone for the prediction of CAD risk. The ratio of total cholesterol levels to HDL was significantly higher in the patient group than in controls $(p<0.05)$; however, as shown in Table 2, a significant correlation was not determined between Gensini scores and total cholesterol/ HDL ratios $(r=0.060, p=0.162)$. Moreover, there was no significant difference between the total cholesterol levels of patients and controls (Table 1).

\section{Serum PONase/HTase Activities and PON1 Gene Polymorphisms}

Serum PONase activity of CAD patients was significantly lower than in control subjects $(135.7 \pm 56.0$ $\mathrm{U} / \mathrm{mL}$ vs $153.8 \pm 62.0 \mathrm{U} / \mathrm{mL}, p<0.05$ ). Serum HTase activity was also significantly lower in CAD patients than in controls $(36.0 \pm 6.1 \mathrm{U} / \mathrm{mL}$ vs $43.0 \pm 4.04$ $\mathrm{U} / \mathrm{mL}, p<0,01)$. Moreover, as shown in Table 2, Gensini scores were negatively correlated with PONase activity $(r=-0.168, p=0.039)$ and HTase activity $(r=$ $-0.164, p=0.006)$. As expected, PONase and HTase activities positively correlated with HDL levels $(r=0.217, p<0.01)$.

The distribution of PON1 polymorphism genotypes in patients and controls is shown in Table 3. 
Table 1. Clinical and biochemical features of the CAD patient group compared to healthy controls

\begin{tabular}{|c|c|c|}
\hline & Control (n: 142) & CAD (n: 128) \\
\hline Sex (male/female) & $60 / 82$ & $88 / 40$ \\
\hline Age (years) & $56.3 \pm 10.7$ & $61.7 \pm 10.9$ \\
\hline BMI $\left(\mathrm{kg} / \mathrm{m}^{2}\right)$ & $28.8 \pm 2.6$ & $26.0 \pm 3.4$ \\
\hline Hypertension (\%) & 45.6 & 61.6 \\
\hline Blood pressure systolic $(\mathrm{mmHg})$ & $126.2 \pm 13.8$ & $131.0 \pm 16.2$ \\
\hline Blood pressure diastolic $(\mathrm{mmHg})$ & $75.5 \pm 9.0$ & $79.5 \pm 8.3$ \\
\hline Lipid-lowering therapy (\%) & 17.0 & 50.7 \\
\hline Glucose $(\mathrm{mg} / \mathrm{dL})$ & $93.0[63-165]^{\mathrm{c}}$ & $100.5[68-272]^{\mathrm{c}}$ \\
\hline Total Cholesterol (mg/dL) & $197.2 \pm 40.0$ & $196.6 \pm 46.4$ \\
\hline $\mathrm{HDL}(\mathrm{mg} / \mathrm{dL})$ & $50.0[27-98]^{\mathrm{a}}$ & $47.5[26-110]^{\mathrm{a}}$ \\
\hline $\mathrm{LDL}(\mathrm{mg} / \mathrm{dL})$ & $115.0[48-238]$ & $115.5[24-243]$ \\
\hline Triglyceride (mg/dL) & $126.5[36-332]^{\mathrm{a}}$ & $150.0[9-659]^{\mathrm{a}}$ \\
\hline VLDL $(\mathrm{mg} / \mathrm{dL})$ & $25.0[8-174]$ & $29.4[2-105]$ \\
\hline Total Cholesterol/HDL & $3.78[1.67-7.26]^{\mathrm{b}}$ & $4.01[1.66-7.92]^{\mathrm{b}}$ \\
\hline PONase $(\mathrm{U} / \mathrm{mL})$ & $153.8 \pm 62.0^{\mathrm{a}}$ & $135.7 \pm 56.0^{\mathrm{a}}$ \\
\hline HTase $(\mathrm{U} / \mathrm{mL})$ & $43.0 \pm 4.04^{b}$ & $36.0 \pm 6.1^{b}$ \\
\hline
\end{tabular}

CAD: Coronary artery disease. a: $p<0.05$; b: $p<0.01$; c: $p<0.001$.

Table 2. The relationship between lipid profile and PON1 activity with the severity and extent of CAD (Gensini Score)

\begin{tabular}{lrc}
\hline & $r$ & $p$ \\
\hline Total cholesterol & 0.143 & 0.086 \\
Triglyceride & 0.082 & 0.329 \\
LDL & 0.124 & 0.136 \\
HDL & -0.020 & 0.809 \\
PONase Activity & -0.168 & 0.039 \\
HTase Activity & -0.164 & 0.006 \\
Total Cholesterol/HDL & 0.060 & 0.162 \\
\hline
\end{tabular}

The genotype frequencies of PON1 polymorphism were determined in 208 subjects.

One hundred ninety-two PON1 genotype frequencies were as follows: QQ homozygote (wild type) 103, QR heterozygotes 93, and RR homozygotes 12. Genotype frequencies for the PON1 Q192R polymorphism were $48 \mathrm{QQ}, 47 \mathrm{QR}, 7 \mathrm{RR}$ in the CAD group and $55 \mathrm{QQ}$, and $46 \mathrm{QR} 5 \mathrm{RR}$ in the control group. There were no significant differences in gene frequencies of PON1 between the CAD group and controls $(p=0.515)$. Allele distribution frequencies were compatible with Hardy-Weinberg distribution in both controls $(p=0.231)$ and patients $(p=0.310)$.

Fig. 1 shows enzyme activities according to PON1 Q192R polymorphism. PONase activity was
Table 3. Genotype distribution and allele frequencies of PON1 Q192R polymorphism

\begin{tabular}{lcc}
\hline Covariates & Control $(n: 106)$ & CAD $(n: 102)$ \\
\hline Genotype & & \\
QQ & 0.52 & 0.47 \\
QR & 0.43 & 0.46 \\
RR & 0.05 & 0.07 \\
$\chi^{2}$ & 1.434 & 1.003 \\
$p$ & 0.231 & 0.310 \\
Allele Frequency & & \\
Q & 0.74 & 0.70 \\
R & 0.26 & 0.30 \\
\hline
\end{tabular}

lowest in the QQ genotype, and there was an increasing trend with increasing $\mathrm{R}$ allele number (from $\mathrm{QQ}$ to RR) $(p=0.001)$. HTase activities were also found to be affected by the PON1 genotype. HTase activity was lowest in QQ genotype, and an increasing trend was found with every $\mathrm{R}$ allele $(p=0.001)$. As shown in Table 4, both CAD and controls with RR genotype had the highest serum PONase and HTase activities. Patients with the remaining genotypes, namely QQ, QR had significantly lower PONase activity than controls in the respective genotype classes $(p<0.05$ and $p$ $<0.01$, respectively). 
A

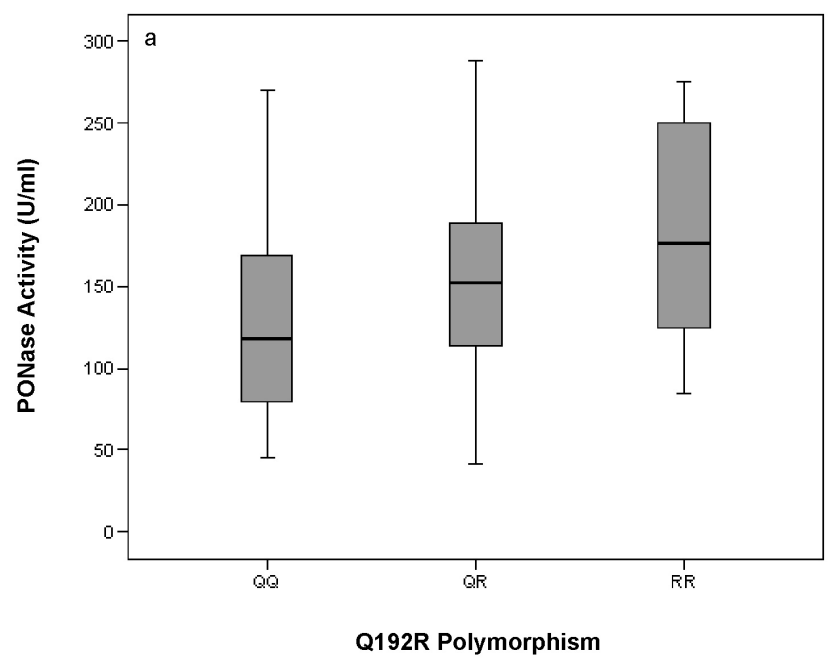

B

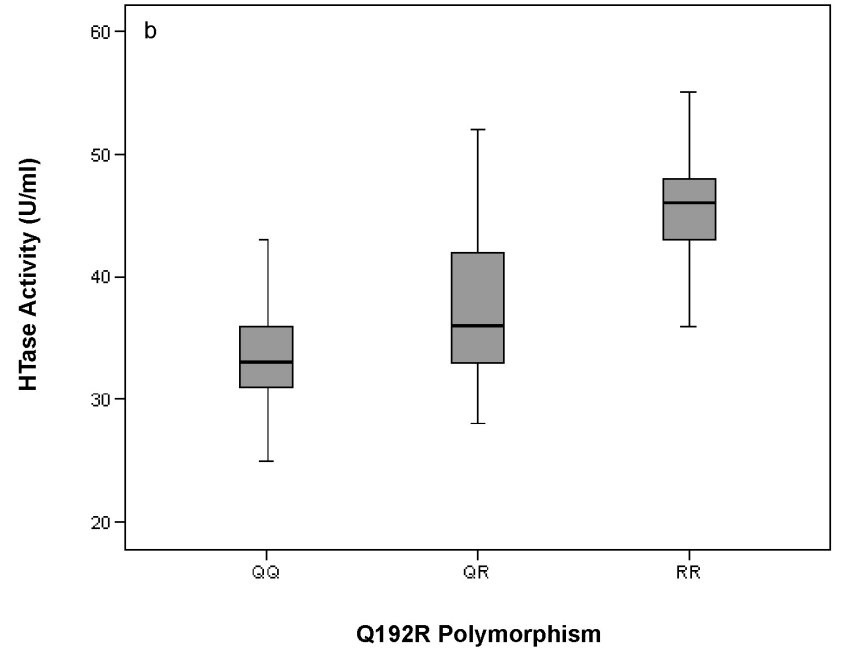

Fig. 1. PONase (A) and HTase (B) activities according to PON1 Q192R polymorphism

Table 4. PONase and HTase activities according to PON1 Q192R genotypes

\begin{tabular}{|c|c|c|c|c|c|c|}
\hline & \multicolumn{3}{|c|}{ PONase Activity (U/ml) } & \multicolumn{3}{|c|}{ HTase Activity (U/ml) } \\
\hline & Total & Control & CAD & Total & Control & CAD \\
\hline${ }^{192} \mathrm{QQ}$ & $128.6 \pm 60.6$ & $142.1 \pm 64^{\mathrm{a}}$ & $113.0 \pm 52.7^{\mathrm{a}}$ & $34.1 \pm 5.9$ & $34.9 \pm 5.0$ & $33.6 \pm 6.4$ \\
\hline${ }^{192} \mathrm{QR}$ & $154.6 \pm 56.6$ & $170.7 \pm 60.0^{b}$ & $141.6 \pm 50.4^{b}$ & $37.8 \pm 5.5$ & $40.0 \pm 5.1^{\mathrm{a}}$ & $36.7 \pm 5.5^{\mathrm{a}}$ \\
\hline${ }^{192} \mathrm{RR}$ & $178.3 \pm 65.9$ & $176.0 \pm 63.3$ & $181.5 \pm 75.3$ & $45.9 \pm 6.6$ & $51.3 \pm 4.0^{\mathrm{a}}$ & $43.1 \pm 4.1^{\mathrm{a}}$ \\
\hline
\end{tabular}

CAD: Coronary artery disease. a: $p<0.05$; b: $p<0.01$

The Relationship of Lipid Profile, PONase/HTase Activities and PON1 Polymorphism with the Severity and Extent of CAD

Angiography was used to evaluate coronary artery stenosis and the Gensini score was used to determine the severity and extent of CAD. In the control group, the Gensini score was zero while in the CAD group it was $\geq 1$. The relationship between the severity and extent of CAD, and the lipid profile or PONase/HTase activities in the patient group are shown in Table 2. Although a positive correlation between the Gensini score and the risk factors for atherosclerosis (serum cholesterol, triglyceride, LDL levels and total cholesterol/HDL ratio) was observed, this correlation was not found to be statistically significant; however, a negative correlation was found between the Gensini score and protective factors such as HDL levels, PONase and HTase activities (Table 2), HTase correlation being more significant than others. The distribution of the Gensini scores according to genotypes was not significant $(p=0.676)$ (Fig. 2).
There were also no differences in lipid profiles between PON1 192Q and 192R genotypes (data not shown).

We also evaluated the relationship between several CAD risk factors and the Gensini score by multivariate logistic regression analysis. Age, sex, HDL level and PONase activity were found to be significantly related with the extent and severity of atherosclerosis (Table 5). ROC analysis was also performed and significant predictive values were found for PONase and HTase activities $(0.622, p<0.05 ; 0.608, p<0.05$, respectively).

\section{Discussion}

The significance of the determination of both PON1 genotype and serum PON1 activity in correlation with disease susceptibility has been strongly highlighted by several authors. To date, multiple studies have examined the association between PON1 polymorphism and $\mathrm{CAD}^{4,13,15-26)}$; however, the vast ma- 


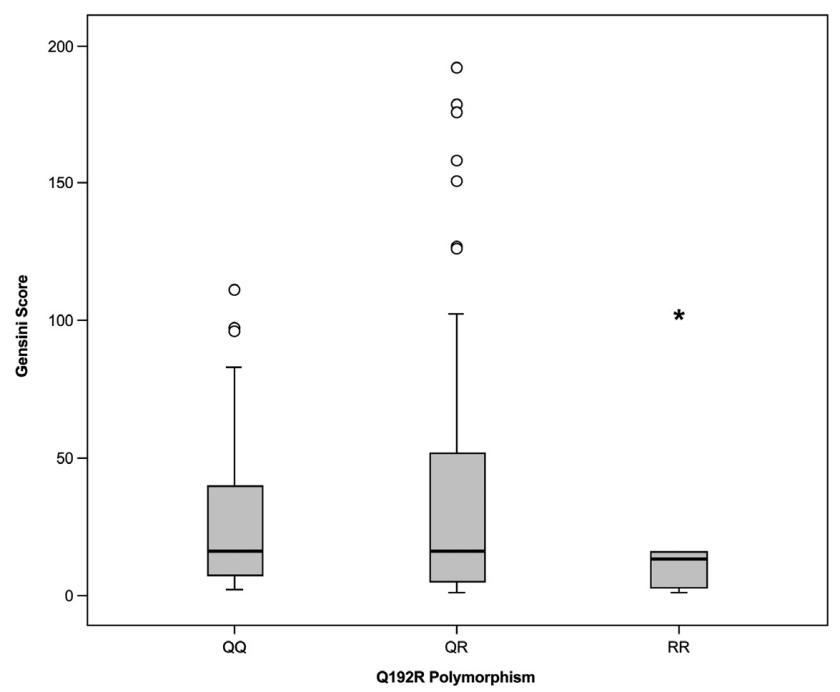

Fig. 2. Distribution of Gensini scores in the CAD group according to PON1 Q192R polymorphism

Outliers $\left({ }^{\circ}\right)$ and extreme values $\left({ }^{*}\right)$ are indicated.

jority of studies neither concurrently assessed PON1 activity nor its relevance with the extent of angiographically documented atherosclerosis. In this study, we aimed at evaluating the relationship of PON1 (Q192R polymorphism and activity) with both CAD risk and the extent and severity of the disease.

It is now well established that PON1 possesses HTase activity that degrades an endogenous substrate, HTL, involved in the oxidative modification of proteins; thus, we evaluated HTase activity in addition to PONase in serum samples. In the literature, two studies have evaluated the relationship among the PON1 genotype, HTase activity and CAD risk ${ }^{33,34)}$. These studies were performed with a limited number of subjects and the control group consisted of asymptomatic individuals. Our study is unique in the way that PONase, HTase activities and PON1 polymorphism are evaluated together and the control group consisted of individuals who do not have angiographically documented disease.

Previous clinical studies that have investigated the relationship between PON1 Q192R polymorphism and CAD have produced inconsistent results, probably because of variations due to the different ethnic origins of study groups ${ }^{14)}$. Conflicting results were also obtained from studies assessing the effect of genotype on enzyme activity. It has been shown that PON1 192R hydrolyzes paraoxon more efficiently while PON1 192Q has higher catalytic activity towards soman and $\operatorname{sarin}^{35)}$. On the other hand, both isozymes hydrolyze phenyl acetate at the same rate. In
Table 5. Logistic regression analysis of CAD risk factors

\begin{tabular}{lrrr}
\hline & OR & 95\%CI & $p$ \\
\hline Age & 1.054 & $1.013-1.096$ & 0.009 \\
Sex & 3.099 & $1.369-6.972$ & 0.007 \\
HDL & 0.935 & $0.92-0.969$ & 0.000 \\
PONase Activity & 0.993 & $0.986-1.000$ & 0.042 \\
\hline
\end{tabular}

an in vitro study, $\mathrm{R}$ allozyme was shown to be less efficient at preventing the oxidation of $\mathrm{LDL}^{4)}$; however, several recent studies have indicated that higher serum PON1 activity is associated with $192 \mathrm{R}$ isozyme. Using paraoxon and HTL as substrates, we have recently demonstrated that PON1 192R hydrolyzed both substrates with higher affinity ${ }^{36}$. Moreover, in two independent clinical studies, higher serum HTase activity was shown to be associated with 192R allele ${ }^{33,34)}$.

In the present study, using either paraoxon or HTL as a substrate, serum PON1 activity was found to be significantly lower in the patient group and the lowest activity was observed in individuals with QQ genotype. Regarding the $\mathrm{R}$ allele an increasing trend was present in $\mathrm{QR}$ and $\mathrm{RR}$ genotypes. Thus, the effect of PON1 Q192R polymorphism on serum PON1 activity was similar to that previously reported $33,34,36$ ). There was no significant difference in PON1 Q192R polymorphism frequency between control and patient groups. The most common genotype was QR heterozygote $(51.5 \%)$, whereas the least common was RR homozygote $(6 \%)$. In a study by Serrano et al., Q allele frequency was significantly lower in CAD patients with respect to controls ${ }^{37)}$; however, Antikianen et al. were unable to confirm such an association between CAD patients and PON1 Q192R polymorphism ${ }^{38)}$. Their allele frequencies and lack of association were in concordance with our results.

Our study did not indicate an association between PON1 Q192R polymorphism and the extent of atherosclerosis (Fig. 2). PONase and HTase activities were found to be more significantly related to the Gensini score than other parameters (Table 2). To our knowledge, no clinical study has evaluated the relationship between PON1 activity and the severity and extent of CAD, but recent studies performed on transgenic mice are informative. PON1 knockout mice are more sensitive to organophospate poisoning and the HDL isolated from these mice is not efficient in preventing the oxidative damage of LDL. When these mice are fed a high fat and high cholesterol diet, they develop atherosclerosis earlier than their normal counterparts $^{39)}$. In another transgenic mouse model where 
PON1 expression increased 2-4 times, atherosclerotic lesions were decreased substantially and HDL particules isolated from these mice effectively protected LDL from oxidation ${ }^{9}$. Those findings support our novel data showing the negative correlation between the severity and extent of CAD and serum PON1 activity.

As shown in Table 2, the negative correlation between the Gensini score and HTase activity was higher and more significant than that with PONase activity $(r=-0.164, p=0.006 ; r=-0.168, p=0.039$, respectively). Thus, decreased HTase activity in CAD patients can account for the increased homocysteinylation of proteins, which in turn leads to atherosclerosis. In support of this concept, it has been shown that homocysteinylation of human HDL decreases its paraoxonase activity ${ }^{40)}$. Furthermore, chronic thiolactone infusion or elevated serum homocysteine levels have been shown to promote atherosclerotic plaque formation in baboons while a similar procedure did not generate atherosclerosis in rabbits that have higher serum HTase levels than primates ${ }^{10)}$. HTL is likely a natural substrate of PON $1^{10-12)}$ and the evaluation of PON1 activity using HTL as a substrate may be more reliable in terms of clinical significance.

Some studies showed that serum PON1 activity is reduced in diabetes, familial hypercholesterolemia, and kidney diseases that are associated with accelerated atherogenesis ${ }^{41-43)}$. We also found a positive correlation between PONase/HTase activities and HDL levels, which is consistent with the literature ${ }^{44)}$. As shown in epidemiological studies, elevated cholesterol, LDL and triglyceride levels and low HDL levels constitute risk factors for atherosclerotic heart disease; however, in atherosclerotic lesions, oxidatively modified HDL is also found ${ }^{45)}$. It has been suggested that the number of HDL particles is not the only factor that determines the antioxidant activity of $\mathrm{HDL}^{6,45-48)}$. HDL can become proatherogenic because of oxidative changes, or dysfunction and/or the lack of protective molecules in its composition that impair its protective function. Low or absent PON1 may lead to CAD with a reduction in the capacity of HDL to prevent LDL oxidation ${ }^{39,47,48)}$; therefore, it is important to evaluate the quality of HDL as well as its quantity. In our study, patients with CAD had a lower HDL level in addition to a higher cholesterol/HDL ratio than control subjects; however, for both PONase and HTase activities, the difference between control and CAD groups was statistically more significant than it was for the lipid profile. Moreover, there was no correlation between HDL levels or the cholesterol/HDL ratio and Gensini scores. It is tempting to speculate that a high HDL level might be protective against coronary artery disease but it may not predict the extent and severity of CAD.

In our study, more than half of the CAD group patients were taking statins. It is likely that, owing to statin use, the average serum total cholesterol and LDL cholesterol levels of this group were lower than expected, and no difference between the lipid profiles of patients and controls was observed (Table 1). Thus, parallel to this lack of difference between lipid profiles, no correlation between the lipid profile and Gensini score was observed. Several reports have investigated the effect of lipid-lowering therapy or drugs on PON1 activity and expression ${ }^{49)}$. Although in the majority of clinical studies it has been shown that serum PON1 activity was modestly increased in patients taking lipid-lowering therapy, no consensus has been reached, probably due to population heterogeneity and assay method differences. In our study, $50.7 \%$ of our patient group were taking statins, but their mean PON1 activity was lower than in the control group in which the statin usage was $17 \%$. Hence, we suggest that the increased PON1 activity of the control group is not related to statin use.

In summary, our study showed that i) there was an inverse relationship between serum PONase/HTase activity and the severity and extent of CAD (HTase being more significant), ii) PONase/HTase activity increased with the presence of $\mathrm{R}$ allele (lowest in $\mathrm{QQ}$ and highest in RR genotype), but Q192R polymorphism was not associated with CAD risk and the extent of the disease, iii) HDL was lower and the cholesterol/HDL ratio was higher in the patient group, but neither the HDL nor cholesterol/HDL ratio was correlated with the severity and extent of CAD. It has been concluded that the determination of serum PONase/HTase activity is more informative than the PON1 genotype or serum HDL level in evaluating the severity and extent of atherosclerotic disease. We also suggest that HTase activity might be a better predictor and prognostic marker in cardiovascular risk assessment for future clinical studies.

\section{Acknowledgements}

This work was supported by TUBITAK (The Scientific and Technological Research Council of Turkey) grant $104 S 437$ and Hacettepe University Scientific Research Unit grant 05.01.101.001. The authors wish to thank Cem Demirpence for the preparation of figures. 


\section{Conflicts of Interest}

The authors declared no competing interest with any group.

\section{References}

1) Harel M, Aharoni A, Gaidukov L, Brumshtein B, Khersonsky O, Meged R, Dvir H, Ravelli RB, McCarthy A, Toker L, Silman I, Sussman JL, Tawfik DS: Structure and evolution of the serum paraoxonase family of detoxifying and anti-atherosclerotic enzymes. Nat Struct Mol Biol, 2004; 11: 412-419

2) La Du BN, Aviram M, Billecke S, Navab M, Primo-Parmo S, Sorenson RC, Standiford TJ: On the physiological role(s) of the paraoxonases. Chem Biol Interact, 1999; 119: 379-388

3) Khersonsky O, Tawfik DS: Structure-reactivity studies of serum PON1 suggest that its native activity is lactonase. Biochemistry, 2005; 44: 6371-6382

4) Mackness B, Mackness MI, Arrol S, Turkie W, Durrington PN: Effect of the human serum paraoxonase 55 and 192 genetic polymorphisms on the protection by high density lipoprotein against low density lipoprotein oxidative modification. FEBS Lett, 1998; 423: 57-60

5) Mackness MI, Arrol S, Durrington PN: Paraoxonase prevents accumulation of lipoperoxides in low density lipoprotein. FEBS Lett, 1991; 286: 152-154

6) Mackness MI, Durrington PN, Mackness B: How highdensity lipoprotein protects against the effects of lipid peroxidation. Curr Opin Lipidol, 2000; 11: 383-388

7) Rosenblat M, Vaya J, Shih DM, Aviram M: Paraoxonase 1 (PON1) enhances HDL-mediated macrophage cholesterol efflux via the ABCA1 transporter in association with increased HDL binding to the cells. Atherosclerosis, 2005; 179: 69-77

8) Rozenberg O, Rosenblat M, Coleman R, Shih DM, Aviram M: Paraoxonase (PON1) deficiency is associated with increased macrophage oxidative stress: studies in PON1knockout mice. Free Radic Biol Med, 2003; 34: 774-784

9) Tward A, Xia YR, Wang XP, Shi YS, Park C, Castellani LW, Lusis AJ, Shih DM: Decreased atherosclerotic lesion formation in human serum paraoxonase transgenic mice. Circulation, 2002; 106: 484-490

10) Jakubowski H: Calcium-dependent human serum homocysteine thiolactone hydrolase: a protective mechanism against protein N-homocysteinylation. J Biol Chem, 2000; 275: 3957-3962

11) Beltowski J: Protein homocysteinylation: a new mechanism of atherogenesis? Postepy Hig Med Dosw, 2005; 59: $392-404$

12) Domagała TB, Łacinski M, Trzeciak WH, Mackness $B$, Mackness MI, Jakubowski H: The correlation of homocysteine-thiolactonase activity of the paraoxonase (PON1) protein with coronary heart disease status. Cell Mol Biol (Noisy-le-grand), 2006; 31: 4-10

13) Mackness B, Davies GK, Turkie W, Lee E, Roberts DH, Hill E, Roberts C, Durrington PN, Mackness MI: Paraoxonase status in coronary artery disease: are activity and concentration more important than genotype? Arterioscler Thromb Vasc Biol, 2001; 21: 1451-1457

14) Mackness M, Mackness B: Paraoxonase 1 and atherosclerosis: is the gene or the protein more important? Free Rad Biol Med, 2004; 37: 1317-1323

15) Imai $Y$, Marita $H$, Kurihara $H$, Sugiyama $T$, Kato N, Ebihara A, Hamada C, Kurihara Y, Shindo T, Oh-hashi Y: Evidence for association between paraoxonase gene polymorphisms and atherosclerotic diseases. Atherosclerosis, 2000; 149: 435-442

16) Gluba A, Pietrucha T, Banach M, Piotrowski G, Rysz J: The role of polymorphisms within paraoxonases (192 Gln/Arg in PON1 and 311Ser/Cys in PON2) in the modulation of cardiovascular risk: a pilot study. Angiology, 2010; 61: 157-165

17) van Himbergen TM, van der Schouw YT, Voorbij HA, van Tits LJ, Stalenhoef AF, Peeters PH, Roest M: Paraoxonase (PON1) and the risk for coronary heart disease and myocardial infarction in a general population of Dutch women. Atherosclerosis, 2008; 199: 408-414

18) Sanghera DK, Aston CE, Saha N, Kamboh MI: DNA polymorphisms in two paraoxonase genes (PON1 and PON2) are associated with the risk of coronary heart disease. Am J Hum Genet, 1998; 62: 36-44

19) Bhattacharyya T, Nicholls SJ, Topol EJ, Zhang R, Yang X, Schmitt D, Fu X, Shao M, Brennan DM, Ellis SG, Brennan ML, Allayee H, Lusis AJ, Hazen SL: Relationship of paraoxonase 1 (PON1) gene polymorphisms and functional activity with systemic oxidative stress and cardiovascular risk. JAMA, 2008; 299: 1265-1276

20) Birjmohun RS, Vergeer M, Stroes ES, Sandhu MS, Ricketts SL, Tanck MW, Wareham NJ, Jukema JW, Kastelein JJ, Khaw KT, Boekholdt SM: Both paraoxonase-1 genotype and activity do not predict the risk of future coronary artery disease; the EPIC-Norfolk Prospective Population Study. PLoS One, 2009; 4: e6809

21) Kuremoto K, Watanabe $Y$, Ohmura H, Shimada K, Mokuno H, Daida H: R/R genotype of human paraoxonase (PON1) is more protective against lipoprotein oxidation and coronary artery disease in Japanese subjects. J Atheroscler Thromb, 2003; 10: 85-92

22) Richter RJ, Furlong CE: Determination of paraoxonase (PON1) status requires more than genotyping. Pharmacogenetics, 1999; 9: 745-753

23) Mohamed RH, Mohamed RH, Karam RA, Abd El-Aziz TA: The relationship between paraoxonase1-192 polymorphism and activity with coronary artery disease. Clin Biochem, 2010; 43: 553-558

24) Jarvik GP, Rozek LS, Brophy VH, Hatsukami TS, Richter RJ, Schellenberg GD, Furlong CE: Paraoxonase (PON1) phenotype is a better predictor of vascular disease than is PON1(192) or PON1(55) genotype. Arterioscler Thromb Vasc Biol, 2000; 20: 2441-2447

25) Jarvik GP, Hatsukami TS, Carlson C, Richter RJ, Jampsa R, Brophy VH, Margolin S, Rieder M, Nickerson D, Schellenberg GD, Heagerty PJ, Furlong CE: Paraoxonase activity, but not haplotype utilizing the linkage disequilibrium structure, predicts vascular disease. Arterioscler Thromb Vasc Biol, 2003; 23: 1465-1471

26) Nakanishi M, Takanami Y, Maruyama T, Murata M, Mo- 
tohashi Y, Nakano S, Uchida K, Maruyama C, Kyotani S, Tsushima M: The ratio of serum paraoxonase/arylesterase activity using an improved assay for arylesterase activity to discriminate PON1(R192) from PON1(Q192). J Atheroscler Thromb, 2003; 10: 337-342

27) Gensini GG. The coronary artery disease scoring and retrieval system of Gensini (Cardscores). In: Coronary arteriography, pp 271-274, Futura Publishing Company, Inc, Mount Kisco, NY, 1975

28) Soydinc S, Davutoglu V, Dundar A, Aksoy M: Relationship between aortic valve sclerosis and the extent of coronary artery disease in patients undergoing diagnostic coronary angiography. Cardiology, 2006; 106: 277-282

29) Gan KN, Smolen A, Eckerson HW, La Du BN: Purification of human serum paraoxonase/arylesterase. Evidence for one esterase catalyzing both activities. Drug Metab Dispos, 1991; 19: 100-106

30) Billecke S, Draganov DI, Counsell R, Stetson P, Watson C, Hsu C, La Du BN: Human serum paraoxonases isozymes $\mathrm{Q}$ and $\mathrm{R}$ hydrolyze lactones and cyclic carbonate esters. Drug Metab Dispos, 2000; 28: 1335-1342

31) Elman GL, Courtney D, Andres V, Featherstone RM: A new and rapid colorimetric determination of acetylcholinesterase activity. Biochem Pharmacol, 1961; 7: 88-95

32) Pinizzotto M, Castillo E, Fiaux M, Temier E, Gaillard RC, Ruiz J: Paraoxanase-2 polymorphisms are associated with diabetic nephropathy in Type II diabetes. Diabetologia, 2001; 44: 104-107

33) Jakubowski H, Ambrosius WT, Pratt JH: Genetic determinants of homocysteine thiolactonase activity in humans: implications for atherosclerosis. FEBS Letters, 2001; 491: 35-39

34) Koubaa N, Nakbi A, Hammami S, Attia N, Mehri S, Ben Hamda K, Ben Farhat M, Miled A, Hammami M: Association of homocysteine thiolactonase activity and PON1 polymorphisms with the severity of acute coronary syndrome. Clin Biochem, 2009; 42: 771-776

35) Ginsberg G, Neafsey P, Hattis D, Guyton KZ, Johns DO, Sonawane B: Genetic polymorphism in paraoxonase 1 (PON1): Population distribution of PON1 activity. J Toxicol Environ Health B Crit Rev, 2009; 12: 473-507

36) Bayrak A, Bayrak T, Demirpence E, Kılınc K: Differential hydrolysis of homocysteine thiolactone by purified human serum 192Q and 192R PON1 isoenzymes J Chromatogr B Analyt Technol Biomed Life Sci, 2011; 879: 49-55

37) Serrato M, Marian AJ: A variant of human paraoxonase/ arylesterase (HUMPONA) gene is a risk factor for coronary artery disease. J Clin Invest, 1995; 96: 3005-3006

38) Antikainen M, Murtomaki S, Syvanne M, Pahlman R, Tahvanainen E, Jauhiainen M, Frick MH, Ehnholm C: The Gln-Arg191 polymorphism of the human paraoxonase gene (HUMPONA) is not associated with the risk of coronary artery disease in Finns. J Clin Invest, 1996; 98: 883-885

39) Shih DM, Gu L, Xia YR, Navab M, Li WF, Hama S, Castellani LW, Furlong CE, Costa LG, Fogelman AM, Lusis AJ: Mice lacking serum paraoxonase are susceptible to organophosphate toxicity and atherosclerosis. Nature, 1998; 394: 284-287

40) Ferretti G, Bacchetti T, Busni D, Rabini RA, Curatola G: Protective effect of paraoxonase activity in high-density lipoproteins against erythrocyte membranes peroxidation: a comparison between healthy subjects and type 1 diabetic patients. J Clin Endocrinol Metab, 2004; 89: 2957-2962

41) Mackness B, Durrington PN, Abuashia B, Boulton AJ, Mackness MI: Low paraoxonase activity in type II diabetes mellitus complicated by retinopathy. Clin Sci, 2000; 98: 355-363

42) Mackness B, Durrington PN, Boulton AJ, Hine D, Mackness MI: Serum paraoxonase activity in patients with type 1 diabetes compared to healthy controls. Eur J Clin Invest, 2002; 32: 259-264

43) Boemi M, Leviev I, Sirolla C, Pieri C, Marra M, James RW: Serum paraoxonase is reduced in type 1 diabetic patients compared to non-diabetic, first degree relatives; influence on the ability of HDL to protect LDL from oxidation. Atherosclerosis, 2001; 155: 229-235

44) Blatter Garin MC, Moren X, J RW: Paraoxonase-1 and serum concentrations of HDL-cholesterol and apoA-I. J Lipid Res, 2005; 47: 515-520

45) Zheng L, Nukuna B, Brennan ML, Hazen SL: Apolipoprotein A-I is a selective target for myeloperoxidase-catalyzed oxidation and functional impairment in subjects with cardiovascular disease. J Clin Invest, 2004; 114: 529541

46) Aviram M: Does paraoxonase play a role in susceptibility to cardiovascular disease? Mol Med Today, 1999; 5: 381386

47) Navab M, Hama SY, Cooke CJ, Anantharamaiah GM, Chaddha M, Jin L, Subbanagounder G, Faull KF, Reddy ST, Miller NE, Fogelman AM: Normal high density lipoprotein inhibits three steps in the formation of mildly oxidized low density lipoprotein: step 1. J Lipid Res, 2000; 41: 1481-1494

48) Navab M, Hama SY, Anantharamaiah GM, Hassan K, Hough GP, Watson AD, Reddy ST, Sevanian A, Fonarow GC, Fogelman AM. Normal high density lipoprotein inhibits three steps in the formation of mildly oxidized low density lipoprotein: steps 2 and 3. J Lipid Res, 2000; 41: 1495-1508

49) Harangi M, Seres I, Harangi J, Paragh G. Benefits and difficulties in measuring HDL subfractions and human paraoxonase-1 activity during statin treatment. Cardiovasc Drugs Ther, 2009: 23; 501-510 